\title{
Ectopic Hormone Secretion Syndrome Associated with Neoplasia
}

National Cancer Institute

\section{Source}

National Cancer Institute. Ectopic Hormone Secretion Syndrome Associated with Neoplasia. NCI Thesaurus. Code C4065.

Abnormal secretion of hormones in conjunction with neoplastic growth occurring anywhere in the body. 